\title{
Hernán Cortés en la Historia general y natural de las Indias de Gonzalo Fernández de Oviedo ${ }^{1}$
}

\author{
Álvaro BARAIBAR \\ Universidad de Navarra (España) \\ abaraibar@unav.es
}

Recepción: 20 de diciembre de 2012 / Revisión: 29 de abril de 2013

Aceptación: 5 de septiembre de 2013 / Publicación: diciembre de 2014

\section{RESUMEN}

La imagen de Hernán Cortés ha sido objeto de múltiples lecturas, contradictorias entre sí en muchas ocasiones. El proceso de construcción del mito sobre los personajes históricos requiere de un proceso de análisis para tratar de identificar las razones de diversa índole que explican unas y otras interpretaciones en sus propios contextos históricos. El presente trabajo estudia una pequeña pero significativa parte de ese proceso de construcción del personaje de Cortés en la Historia de Gonzalo Fernández de Oviedo. El objetivo principal del mismo es analizar de qué modo el proceso de escritura de la crónica, así como las ideas del cronista incidieron en la forma en que el conquistador se nos muestra en la que fue la primera crónica de Indias.

Palabras clave: Literatura colonial, crónicas de Indias, Gonzalo Fernández de Oviedo, Hernán Cortés, Nueva España, siglo XVI.

\section{Hernán Cortés in Gonzalo Fernández de Oviedo’s Historia General y Natural de las Indias}

\begin{abstract}
The image of Hernán Cortés has been interpreted from numerous different and frequently contradictory perspectives. The process of creating mythical figures from historical characters requires an analysis of the reasons that may explain the variety of interpretations, each within its own historical context. This article studies a small but significant part of this process in the creation of Cortés' character in the Historia, by Gonzalo Fernández de Oviedo. The main aim is to analyse how the process of writing the chronicle and Fernández de Oviedo's own ideas, influenced the way the author presented the conqueror Hernán Cortés in the first chronicle of the Indies.
\end{abstract}

Keywords: Colonial Literature, Chronicles of the Indies, Gonzalo Fernández de Oviedo, Hernán Cortés, Conquest of Mexico, Mexico, $16^{\text {th }}$ century.

Sumario: 1. Introducción. 2. Hernán Cortés frente a Cristóbal Colón y Diego Velázquez. 3. Hernán Cortés: el gran conquistador. 4. Conclusiones. 5. Referencias bibliográficas.

1 Este trabajo forma parte de los resultados del proyecto HAR2012-31536, Discurso y poder, lengua $y$ autoridad en el mundo hispánico (siglos XVI-XVII), subvencionado por el Ministerio de Economía y Competitividad. 


\section{INTRODUCCIÓN}

Hernán Cortés es uno de esos nombres de la Historia a los que se hace protagonista o responsable de grandes acontecimientos. Su figura ha sido objeto de diferentes interpretaciones de signos opuestos. La Historia y la Literatura, ni neutras ni asépticas, impulsadas por motivaciones de carácter político, ideológico o personal, y en el caso de la Literatura en uso de la libertad poética, han construido el personaje más allá de la persona, interpretando sus acciones, decisiones y hasta sus rasgos físicos o de carácter dentro de un marco de sentidos ajenos a veces a la realidad histórica.

Poco o nada tienen que ver entre sí las imágenes de Cortés que podemos encontrar en obras de sus propios contemporáneos. Así, Francisco López de Gómara se refiere a él como alguien cuyo nombre y memoria debían prevalecer por ser "quien conquistó tanta tierra, convirtió tantas personas, derribó tantos dioses, impidió tanto sacrificio y comida de hombres" ${ }^{2}$. Por contra, Bartolomé de las Casas no ve en el conquistador sino la codicia propia de todos los españoles que viajaron a las Indias Occidentales y afirma que Cortés tiene engañado al mundo gracias a la labor de algunos historiadores con los que compartía el mismo fin, "hacerse ricos de la sangre de aquestas míseras y humildes y pacíficas gentes" .

Hernán Cortés ha sido objeto de una leyenda rosa y una leyenda negra ${ }^{4}$. Historia y Literatura son instrumentos poderosos a la hora de socializar mensajes, ideas y valores. En este sentido, Cortés condensa en su persona aspectos que lo trascienden como individuo y que hacen de él un símbolo, bien sea de la conquista y del esplendor del imperio castellano o de la barbarie y exterminio de buena parte de la población indígena americana; de la extensión de la palabra divina y la evangelización de tantas almas o de la violencia ejercida por la cultura dominante ${ }^{5}$.

El proceso de construcción del mito, de la leyenda, precisa de un trabajo similar de deconstrucción que, lejos de juicios críticos e hipercríticos, se centre en analizar los contextos históricos y literarios, ideológicos y políticos, así como las coyunturas personales y concretas que lo hicieron posible. En las próximas páginas me propongo analizar un pequeño pero significativo fragmento de este proceso histórico: la forma en que Gonzalo Fernández de Oviedo trató a Hernán Cortés en su Historia general y natural de las Indias y las razones que lo explican.

2 López de Gómara, 2000, p. 40.

3 Las CASAS, 1951, vol. III, p. 222.

4 Mira Caballos, 2010, esp. pp. 27-47.

5 La bibliografía sobre la figura de Cortés en la Historia y la Literatura es muy abundante. Ver al respecto Delgado Larios, 1990 y Mira Caballos, 2010, para una bibliografía más actualizada. Tal y como afirma Delgado Gómez, 1993, p. 21, el juicio historiográfico había sido muy favorable a Cortés, con la excepción de Las Casas, hasta que en fechas recientes el nacionalismo mexicano, por un lado, y la corriente indigenista, por el otro, cambiarán el enfoque de algunos estudios. Delgado Gómez contrapone a MADARIAGA, 1975 [1941] y Eulalia Guzmán (en su ed. de las Cartas de Cortés publicada en 1958) resalta también la existencia de "una tercera vía más ecuánime", en la que ubica a Manuel OrozCo y BerRA, 1880 y 1938 y, posteriormente, a Henry R. Wagner, 1944; Silvio Zavala, 1964 y 1985 (entre otros); J. H. Elliott, 1965 y 1971; Miguel León Portilla, 1974; y José Luis Martínez, 1990. Ver también Bennassar, 2002, esp. pp. 241-257. Para la presencia de Cortés en la Literatura del Siglo de Oro ver ReYNoLds, 1978. 


\section{HERNÁN CORTÉS FRENTE A CRISTÓBAL COLÓN Y DIEGO VELÁZQUEZ}

Resulta significativa la única mención que Gonzalo Fernández de Oviedo hace en el Sumario al respecto de las gestas de Hernán Cortés y de la conquista de la Nueva España. Cuando, en el capítulo 9, Oviedo habla "De las cosas de la Tierra Firme", excluye todo lo relativo a la Nueva España

porque aquello Hernando Cortés lo ha escripto según a él le ha parecido, y hecho relación por sus Cartas, y más copiosamente yo lo tengo asimismo acomulado en mis Memoriales por información de muchos testigos de vista, como hombre que he deseado inquerir y saber lo cierto ${ }^{6}$.

El Sumario no se detiene en la historia del descubrimiento y la conquista, sino que se centra en una historia natural del Nuevo Mundo, de modo que no sería acertado entender el silencio sobre Hernán Cortés y la Nueva España como algo llamativo. Hay en este pasaje, sin embargo, otro aspecto que considero especialmente interesante en nuestro cronista. Oviedo explica cómo Cortés había sido en realidad el tercero de los capitanes - después de Francisco Hernández de Córdoba y Juan de Grijalva - enviados por el adelantado Diego Velázquez a explorar "aquella tierra y costa". Pero, además, y por encima de este aspecto, lo importante para Oviedo, lo que el madrileño quiso poner de relieve era que todos los éxitos relativos a las Indias Occidentales, todos los nuevos descubrimientos habían sido posibles gracias a Cristóbal Colón. Oviedo quiso matizar el papel desempeñado por cada cual con las siguientes líneas:

Francisco Hernández de Córdoba, descubrió, o mejor diciendo, tocó primero en aquella tierra (porque descobridor, hablando verdad, ninguno se puede decir, sino el almirante primero de las Indias, don Cristóbal Colom [...], por cuyo aviso y causa los otros han ido o navegado por aquellas partes) ${ }^{7}$.

Ya desde aquellas primeras páginas publicadas en 1526, Oviedo construirá el personaje de Hernán Cortés con Cristóbal Colón como límite, podríamos decir, de la grandeza del personaje. En lo que al Descubrimiento se refiere, Oviedo resalta la gran hazaña del almirante en la misma medida que modulaba y limitaba los méritos del conquistador. Se trata de una idea que va a ser una constante en nuestro cronista y que se repite en la Historia.

6 Fernández de Oviedo, 2010, pp. 107-108. Las citas siguen los criterios de modernización del texto adoptados por el Grupo de Investigación Siglo de Oro (GRISO) de la Universidad de Navarra que se pueden consultar en ARELLANO, 2007.

7 Ibídem, p. 108. Más adelante, en el mismo Sumario, Oviedo compara los logros de Colón y Hércules y resalta cuánto más lejos había llegado aquel y dice: "pues que Hércoles fue el que aquello poco navegó y por eso dicen los poetas que dio la puerta al Occéano, etc., por cierto señor, aunque a Colom se hiciera una estatua de oro, no pensaran los antiguos que le pagaban si en su tiempo él fuera”, p. 150. 
Para Oviedo Colón es el "primer inventor e descubridor e almirante destas Indias" . Es también "animoso experimentador", ya que él y no otro fue "el primero que en España enseñó a navegar el amplísimo mar Océano por las alturas de los grados de sol y Norte, e lo puso por obra". A Colón corresponde el mérito de ser "el primero descubridor" de unas tierras "tan incónitas e apartadas de todo lo que Tolomeo e otros cosmógrafos escribieron”:

a solo Colom, después de Dios, le deben los reyes de España pasados e Católicos, e los presentes y por venir, y no solamente toda la nación de los señoríos todos de sus majestades, mas aun los reinos extraños, por la grande utilidad que en todo el mundo ha redundado destas Indias ${ }^{10}$.

Volviendo a Hernán Cortés, Gonzalo Fernández de Oviedo, en la Historia, incide en la imagen del conquistador como tercer capitán enviado a la península de Yucatán ${ }^{11}$. En opinión de Oviedo, Cortés, además de no ser el primero en pisar tierras de Yucatán, había sido desleal para con Diego Velázquez, que era quien había hecho posible la expedición del extremeño al continente y a quien correspondían los méritos y las mercedes que había otorgado el propio monarca, tal y como relata el cronista madrileño ${ }^{12}$. Tras el regreso de Juan de Grijalva, Diego Velázquez envió a un clérigo llamado Benito Martín con muestras del oro hallado en Yucatán y con una relación de los descubrimientos realizados para informar al rey y este, en reconocimiento de sus servicios, lo nombró Adelantado de todo lo que había descubierto y le hizo otras mercedes ${ }^{13}$. El rey, además, "le escribió generosamente, dándole las gracias por lo hecho, e animándole para que continuase aquel descubrimiento" 14 .

Llegados a este punto del relato, Oviedo parece sentirse en la obligación de explicar que no pretende quitar a Cortés el

loor que él merezca en las cosas que adelante en la segunda parte desta General Historia le tocaren. Pero no apruebo lo que él y otros dicen, porfiando que Cortés y otros fueron a sus proprias despensas a aquellas tierras, porque aunque así fuese [...], este loor por de Diego Velázquez y no de otro le tengo, pues él dio princi-

8 FERNÁNDEZ DE Oviedo, 1992, vol. I, pp. 14-15.

9 Ibídem, vol. I, pp. 20-21.

10 Ibídem, vol. I, p. 15. Por otro lado, Carrillo ha resaltado el hecho de que Oviedo sitúe la narración del descubrimiento de Colón como "punto de partida y base del discurso sobre el Nuevo Mundo", siendo algo equivalente al libro "sobre cosmología en la obra de Plinio respecto al ecumene romano", CARRILlo, 2004, pp. 103-104.

11 Fernández de Oviedo, 1992, vol. II, p. 116.

12 Tomás y Valiente, 1988, p. 170 se refirió a ello como una "ilegitimidad de origen" de la conquista de Cortés. Sobre el conflicto entre Cortés y Velázquez, ver ZAVALA, 1964. PASTOR, 2008, p. 123, ha escrito sobre la actitud de Cortés hacia Velázquez como una "situación de obediencia formal y declarada, pero de rebelión de hecho". Mientras, Ramos, 1992, esp. pp. 41-59 y 165-204, ha aportado un enfoque netamente distinto sobre el origen y desarrollo de la expedición de Cortés a Tierra Firme.

13 Oviedo, que conocía al clérigo por haber viajado con él a tierras americanas en 1514, afirma haber visto aquellos objetos estando en Barcelona en mayo de 1519. El cronista quiere dar un plus de veracidad a esta parte de la historia presentándose como testigo de vista de los acontecimientos; comp. FerNÁNDEZ DE OvIEDO, 1992, vol. II, p. 148.

14 Ibídem, vol. II, p. 148. 
pio a todo lo que subcedió de la Nueva España [...]; y después se quedó con todo Hernando Cortés, porque el tiempo y su ventura y la desdicha de Diego Velázquez, por alguna dispensación de arriba, así lo causaron ${ }^{15}$.

Oviedo quiere dejar clara constancia de que fue Velázquez quien envió a Cortés como su teniente y explica cómo él había conseguido el poder e instrucción que Diego Velázquez diera a Cortés en Santiago, puerto de la Fernandina, el 23 de octubre de 1518, ante el escribano público Alonso de Escalante. Al año siguiente “estando enseñoreado Cortés de parte de la tierra", se olvidó de Velázquez y envió directamente al emperador una relación de lo que había visto así como abundantes muestras del oro y joyas encontrados. Nuevamente Oviedo es testigo de los hechos en Sevilla a finales de 1519, cuando se disponía a regresar a las Indias Occidentales ${ }^{16}$.

El 22 de octubre de 1522 una provisión del rey quiso resolver la situación nombrando a Hernán Cortés gobernador de México. El monarca dejaba que las disputas entre Velázquez y Cortés se dilucidaran en el Consejo Real de Indias y mientras tanto el Adelantado no enviaría armada alguna a la Nueva España. La "solicitud y buen negociar" de Cortés habían sido claves en ello. Al mismo tiempo, las noticias de las riquezas de aquella tierra y de su generosidad hacían que Cortés fuera "amado de los que con él militaban, e Diego Velázquez aborrecido"17.

Diego Velázquez murió en 1524 en unas condiciones que no eran, en opinión de Oviedo, sino un buen ejemplo del viejo proverbio: "Matarás y matarte han; y matarán quien te matare"18. Diego Velázquez, que había sido "riquísimo hombre", acabó

pobre y enfermo y descontento, y la burla que él había hecho al almirante don Diego Colom en se le quedar con la gobernación de la isla de Cuba, esa misma hizo dél, y más por entero, Hernando Cortés, en se le quedar con la gobernación de la Nueva España ${ }^{19}$.

Así pues, la primera imagen que Oviedo nos transmite de Hernán Cortés no es especialmente laudatoria. El mérito del descubrimiento del Yucatán no pertenecía al conquistador español, pues no era sino el tercero en pisar aquella tierra; no acudió por sus propios medios, sino como teniente de Diego Velázquez; y, en tercer lugar, lejos de ser leal a su superior, se quedó con unas tierras y un mérito que no le correspondían.

Sin embargo, en lo que a la relación entre Cortés y Diego Velázquez se refiere, la opinión de Oviedo y su manera de presentar al personaje sufrirá una evolución más adelante a lo largo del libro 33 de su Historia, en el que se narra la conquista de la Nueva España. El título del primer capítulo de este libro 33 es significativo al incidir una vez más en la deslealtad de Cortés cuando dice "cómo se apartó, por exquisitas formas, de la obidiencia e amistad del adelantado Diego Velázquez, su superior" 20.

15 Ibídem, vol. II, p. 149.

16 Ibídem, vol. II, pp. 149-150.

17 Ibídem, vol. II, p. 150.

18 Ibídem, vol. II, p. 149. El cronista añade un pequeño excurso con varias citas de autoridades sobre esta cuestión.

19 Ibídem, vol. II, p. 150.

20 Ibídem, vol. IV, p. 8. 
Cuando relata cómo Cortés envió en 1519 a dos procuradores con regalos para el emperador sin avisar a Diego Velázquez, Oviedo explica cuáles eran las intenciones de Cortés:

iban con el presente que es dicho, e a dar relación de los servicios de Cortés, e procurar aniquilar los de quien a aquella tierra le envió con esta armada (que era Diego Velázquez) como de la historia se puede fácilmente colegir conforme a verdad ${ }^{21}$.

Uno de los capítulos más interesantes en este sentido es el decimosegundo, donde se narra cómo Diego Velázquez envió a Pánfilo de Narváez a apresar a Cortés y cómo fue este el que salió victorioso del enfrentamiento. Oviedo, fiel a la estructura del libro, sigue la versión de Cortés, pero nos avisa de que, como era de esperar, la explicación de los hechos que daba Pánfilo de Narváez era totalmente contraria y tildaba a Cortés de traidor y "alevoso e tirano, e ingrato a su señor e a quien le había enviado a la Nueva España"22. Oviedo, cronista de Indias e imparcial en estas rivalidades entre conquistadores, no quiere "ser odioso a ninguna de las partes", pero no se resiste a dar su opinión. Analizando la evolución de los acontecimientos, Oviedo resalta de Narváez el mal hacer de quien se había dejado apresar y no había tomado las debidas precauciones. Por su parte, en el caso de Cortés cree que debió haber acatado la autoridad de Narváez, ya que era "claro e notorio" que el adelantado Diego Velázquez le había mandado al Yucatán y que, por tanto, "era parte, segund derecho, para le enviar a remover, y el Cortés obligado a le obedecer"23. Así, insiste Oviedo en que

yo no hallo qué loar a Cortés en su desobidiencia, ni a él le quedó nada por usar en sus cautelas, para se quedar en opinión y en oficio ajeno, contra la voluntad de cuyo era e se lo dio y encomendó; ni a Pánfilo de Narváez le faltó la penitencia de su descuido, ni a Diego Velázquez quiso la fortuna dejar de destruirle, ni a Cortés de favorecerle para salir con su propósito, como ha salido ${ }^{24}$.

Oviedo termina el capítulo con una referencia a que más allá de las disputas humanas, quien resuelve el devenir de los acontecimientos no es sino la Providencia divina. En estas cuestiones, no siempre se aplica "la razón que a los hombres les parece que es justa, sino otra definición superior e juicio de Dios que no alcanzamos". En lo que a la providencia de Dios se refiere "no nos conviene platicar ni pensar, sino que aquello conviene". Y siendo así, "quitado aparte este escrúpulo de no acudir Cortés a Diego Velázquez", en lo demás "valerosa persona ha seído e para mucho". En definitiva,

que si bien o mal hicieron, aunque en el suelo no vean los hombres cómo se determinan estas cosas, ya sabemos que es cuenta corriente para adelante, e que ha de llegar todo a aquel tribunal infalible, e donde no ha de faltar justicia ni encobrirse delicto ni cosa mal hecha, ni quedar sin galardón lo bien hecho, sin excepción de personas ${ }^{25}$.

21 Ibídem, vol. IV, p. 10.

22 Ibídem, vol. IV, p. 59.

23 Ibídem.

24 Ibídem.

25 Ibídem, vol. IV, pp. 59-60. 
En este caso y en otros parece como si Oviedo justificara ciertas disputas entre capitanes y conquistadores a la hora de que cada cual defienda sus propios intereses. De hecho, hay otro pasaje poco más adelante en el que Oviedo regresa sobre la misma idea y reflexiona sobre si la forma de proceder de Cortés había sido la correcta o no. Me refiero al momento en que Oviedo nos cuenta cómo habían llegado a Veracruz los supervivientes de una expedición de dos navíos enviada por Francisco de Garay al río grande de Pánuco. Oviedo da a entender que si bien Cortés afirma que dio libertad a estos españoles de irse si así lo deseaban, tal vez ocurriera justo lo contrario, de modo que aquellos cristianos terminarán engrosando las filas de sus huestes:

Otros dicen en esto muy al revés, e que se les daba buenas palabras, e que por otra parte los impidieron e tovieron forma para que de necesidad se quedasen en la tierra, e los navíos al través. Pero dejemos estas contiendas, que usanza es de los hombres de guerra usar de todas sus cautelas posibles para que se aumente su ejército, en especial tras una necesidad tan notoria como la que en esa sazón tenía Cortés de gente ${ }^{26}$.

Avanzado el relato de las hazañas de la conquista de la Nueva España, tomada ya Temistitán ${ }^{27}$, Cortés es avisado de la llegada a Veracruz de Cristóbal de Tapia con provisiones reales para ejercer como gobernador de aquellas tierras. Oviedo en este caso toma claro partido por Cortés y justifica su actuación. Existen para ello, como podemos comprobar en la exposición de Oviedo, tres razones fundamentales. En primer lugar, el nombramiento de Tapia se llevó a cabo en ausencia del emperador Carlos V, que se encontraba en Flandes. Gobernaban en su nombre en aquellos momentos el cardenal Tortosa, junto con el condestable de Castilla, Íñigo de Velasco, y el almirante de Castilla, Fadrique Enríquez. En esta decisión, "sospechó Hernando Cortés", había influido el obispo de Burgos, Joan Rodríguez de Fonseca, "a quien se daba principal lugar e tenía la presidencia en las cosas de las Indias, y era amigo e favorecedor del adelantado Diego Velázquez" ${ }^{28}$. Así pues, el nombramiento no había sido obra del emperador, sino que se debía a los manejos de quien aparece como "enemigo de Cortés", y este, como alguien dotado de la diligencia y curiosidad que el escritor romano Flavio Vegecio Renato reclamaba a los buenos capitanes, "no dio lugar a ser descompuesto del primero bote o grita". Y continúa Oviedo: "no parezca a ninguno fealdad que el valeroso corazón desee señorío, con tanto que no se adquiera indebidamente" 29 . Y en este sentido, "si buena fue la astucia de Darío para quedar señor, que no fue mala ni desconviniente la de Hernando Cortés para quedarse por capitán general en aquella tierra hasta saber la voluntad de su rey". Oviedo juega aquí con

26 Ibídem, vol. IV, pp. 75-76.

27 Temistitán es el nombre con el que Oviedo y otros cronistas (fray Toribio de Benavente entre otros) se refirieron a Tenochtitlán. En adelante mantengo el topónimo empleado por el cronista, aunque indicaré la primera vez que aparezca la forma más conocida en aquellos casos que ayude a una mejor comprensión del texto.

28 Fernández de Oviedo, 1992, vol. IV, p. 157. Más adelante, en el cap. 35, Oviedo copia “a la letra” un pasaje de la cuarta carta de Cortés donde se queja de los manejos del obispo de Burgos para actuar contra Cortés a espaldas del propio emperador, pp. 167-168. Para más información sobre el obispo Fonseca puede verse SAgARRA GAMAZO, 1990.

29 Fernández de Oviedo, 1992, vol. IV, p. 159-160. 
ventaja, ya que, como hemos comentado antes, sabe que poco después Carlos V no solo aprobaría "su persona e servicios", sino que además le daría "títulos de honor" 30 .

La segunda de las razones que acompañan a Cortés en esta evolución de la perspectiva de Oviedo se fundamenta en el mejor "servicio de sus majestades e bien de la tierra", ya que era Cortés el que mantenía a los indígenas como vasallos del rey. El simple hecho de que Tapia hubiera llegado y "publicado que iba por gobernador e capitán de aquellas partes" provocó gran alboroto y un intento de alzamiento impulsado por algunos naturales. Así pues, Cortés era imprescindible para conseguir la definitiva pacificación de aquellas provincias, que era a su vez lo que más convenía a los intereses del rey y de Castilla ${ }^{31}$.

Y la tercera de las razones la expone Oviedo en forma de pregunta directa a los lectores:

¿Paréceos, letor, que para la safisfación e paga e gratificación de mercedes que esperaban aquellos caballeros e hidalgos que tan señalado e arduo e dificultoso cerco tovieron, e que con sus vidas e sangre le sostuvieron e acabaron, que con un gobernador que iba de nuevo e que no lo había hecho ni visto ni aun entendido, no conocía los méritos de cada uno, que los podía así contentar ni galardonar como aquel que en su compañía e presencia se halló con ellos, e con cuyo consejo e prudencia se consiguió la victoria? ${ }^{32}$.

Las mercedes y la gloria correspondían a quien por las armas las habían ganado y merecido ${ }^{33}$. Era totalmente injusto que viniera alguien a asumir la gobernación de un territorio cuando en él estaban quienes lo habían obtenido con su esfuerzo y con el riesgo de sus propias vidas. Se trata de una idea muy presente no sólo en Oviedo sino en muchos otros de los primeros conquistadores ${ }^{34}$.

A pesar de ello, unos capítulos más adelante Oviedo se escandaliza por unas palabras escritas por Cortés en la cuarta de sus cartas. El conquistador había sido informado de cómo Diego Velázquez, desde Cuba, hacía todo lo posible para que no llegara gente a la Nueva España y abusaba de su posición con quienes pasaban por la isla procedentes de su gobernación. Cortés se había permitido el atrevimiento de escribir al emperador diciéndole que indagaría qué había de cierto en ello y que si encontraba que era verdad, "pensaba de enviar el Diego Velázquez e prenderle, e preso enviarle a su majestad" 35 .

Oviedo es rotundo a este respecto. Cortés "no tenía qué hacer" en la isla de Cuba frente a su legítimo administrador, que era, además, quien le había enviado por su

\footnotetext{
30 Ibídem, vol. IV, p. 160.

31 Más adelante el cronista se refiere al alboroto que se sucedió, llegando a la rebelión en el caso de la provincia de Tutebeque, al rumor que se extendió de que Cortés se volvía a Castilla, p. 166.

32 Fernández de Oviedo, 1992, vol. IV, p. 159.

33 "Muchos son los trabajos que en esta parte se han padecido, e grandes los merecimientos e servicios de tan experimentado capitán e tan diestros e animosos conquistadores, hasta la cual expiriencia no se puede alguno intitular ni tener por maestro de tal arte sin que le cueste años e sangre, e haya probado las miserias e desaventuras y sed y hambre, pobreza, desnudez y otros inumerables trabajos que andan debajo de la militar disciplina", asevera Oviedo poco más adelante, p. 171.

34 Ver al respecto, entre otros, VARGAS MACHUCA, 2003, pp. 154-156.

35 Fernández de Oviedo, 1992, vol. IV, p. 191. Ver el pasaje en Cortés, 1993, pp. 516-517.
} 
capitán. Aquellas palabras, especialmente por el hecho de haber sido escritas y dirigidas a su majestad, fueron juzgadas incluso como "desacatadas" por parte de "personas graves" ${ }^{36}$. Se trataba de una falta cometida contra la autoridad de un legítimo gobernante designado precisamente por el rey que era a quien Cortés había dirigido el escrito. Oviedo no da importancia a si Cortés apresaba o no a Velázquez. Insiste en que aquel era persona "de mucho e grand mérito, e que el estado que tiene e otro muy mayor cabe en él. Pero junto con esto, no le loo ni me parecen tolerables tales palabras in scriptis".

Como en tantas otras ocasiones, él había sido testigo del revuelo que provocaron aquellas palabras en la Corte porque había estado presente cuando Diego de Soto llevó la carta de Cortés y pudo leer el original ${ }^{37}$. Pero en Oviedo hay, además, un segundo motivo de alarma. Oviedo es un gran ejemplo de la aplicación de una "lógica administrativa y jurisdiccional" al proceso de conquista de América. En este sentido, México dependía tanto histórica como jurisdiccionalmente de Cuba y de su legítimo gobernador, que en aquellos momentos no era otro que Diego Velázquez ${ }^{38}$. Las palabras dirigidas al monarca eran, por tanto, una falta a la autoridad imperdonable y no cabía en este caso una mirada más comprensiva, como sí había tenido Oviedo en otras ocasiones. Francisco Tomás y Valiente se refirió en uno de sus trabajos al concepto de monarquía que tenía Cortés y cómo entendía su fidelidad para con la persona del emperador ${ }^{39}$. En este sentido, estas palabras no se podrían interpretar como una deslealtad, pero sí como un signo de una cierta altivez o altanería, en palabras empleadas por Tomás y Valiente ${ }^{40}$.

Veamos a continuación de qué modo Oviedo va construyendo la imagen de Cortés como gran conquistador.

\section{HERNÁN CORTÉS: EL GRAN CONQUISTADOR}

Oviedo dedicó el extenso libro 33 de su Historia a la conquista de la Nueva España, desde el desembarco de Hernán Cortés hasta la muerte del conquistador. El cronista nos avisa de que para que "más puntualmente se diga el discurso de la historia de Hernando Cortés, quiero seguir en parte la relación de sus mesmas cartas, escriptas a César" ${ }^{41}$. Poco antes se había lamentado veladamente de que, teniendo "cédulas reales para que los gobernadores me envíen relación de lo que tocare a la historia de sus gobernaciones", cuando escribió a Cortés para que le enviase la suya este le remitió "a unas cartas misivas que le escribió a su majestad [...] e no curó de más". Siendo

36 Ibídem, vol. IV, p. 191.

37 Ibídem, vol. IV, p. 192.

38 Carrillo Castillo, 2004, p. 115. Esta misma lógica se trasladará a la estructura de la obra y así, en el "Proemio" del libro 17, dedicado a Cuba, Oviedo nos explica cómo, "siguiendo la orden e verdad de su descubrimiento", tras hablar de la Española y San Juan, era el momento de detenerse en Cuba y referir "cómo e por quién desde aquesta isla se descubrieron Yucatán y la Nueva España”, Fernández de OvIEDO, 1992 , vol. II, p. 110

39 Tomás y VALIente, 1988, pp. 169-170.

40 Ibídem, p. 173.

41 Fernández de Oviedo, 1992, vol. IV, p. 11. 
así, fiel a la verdad, Oviedo nos asegura que "de esas, e de lo que me informaron, de todo haré memoria en este libro XXXIII"42.

En efecto, la estructura del relato de la conquista de la Nueva España tiene dos partes claramente diferenciadas. En la primera, Oviedo traza el curso de la historia "siguiendo el tenor de lo que Hernando Cortés escribió al emperador nuestro señor" en sus cartas de relación ${ }^{43}$. Es el núcleo principal del libro, la parte más extensa y que, además, estaba presente desde muy pronto en el proceso de escritura y reescritura de la Historia ${ }^{44}$. En la segunda parte, mucho más breve y de menor relevancia -a partir del capítulo 44-, añade otras informaciones que no siempre coinciden con la versión que diera el conquistador ${ }^{45}$. Oviedo incorpora estos capítulos como complementarios a lo ya relatado y lo hace posteriormente, entre 1544 y 1549 . Si en algún caso los datos eran contradictorios, no debía sorprendernos, nos dice el autor, ya que era algo que ocurría constantemente ${ }^{46}$. Oviedo deja, en este sentido, que sea el propio lector quien decida sobre unas informaciones que él ha recopilado teniendo como máxima el haber acudido a "personas que merecen ser creídos" y que en todo se hallaron presentes ${ }^{47}$.

Este libro 33 es el lugar en el que se ensalza la excepcionalidad de Cortés en el arte militar y donde Oviedo construye la imagen del héroe con diversas referencias a personajes y pasajes de la Antigüedad ${ }^{48}$. Así, Cortés es un "denodado capitán" que lucha al frente de sus soldados con valor ${ }^{49}$, alguien que merece ser comparado con Horacio Cocles, un mítico héroe romano, por la defensa que hizo de un puente en solitario tras comprobar que los que con él iban habían caído ${ }^{50}$. En opinión de Oviedo, para quien el arte militar es superior al resto, el episodio de la salida de Temistitán hace de Hernán Cortés y de los que con él se hallaron más gloriosos "que a capitán ni mílites de todos cuantos en estas partes e Indias han meneado las armas". La conquista de la Nueva España precede a cualquier otra de las que los españoles habían llevado a cabo en el Nuevo Mundo. Así "se puede muy bien entender e colegir, sin ofensa de ninguno, si apartadas las pasiones e afición particular, alguno e todos los que se quisieren ocupar en este juicio lo quisieren entender". Cortés bien merecía aquella "palma"51.

\footnotetext{
42 Ibídem, vol. IV, p. 8.

43 Ibídem, vol. IV, p. 42. Incluso en el pasaje en que se narra cómo Diego de Velázquez envió a Pánfilo de Narváez para revocar los poderes que había dado a Cortés, Oviedo sigue la versión del conquistador, aunque en este caso incluye también la de Narváez y se permite algunos juicios y opiniones personales, pp. 52 y ss.

44 Ver al respecto Carrillo Castillo, 2004, pp. 107-141. Concretamente sobre el libro 33, ver pp. 114-115 y 130 .

45 Un estudio centrado en la excepcionalidad del capítulo 54 se puede ver en MYERs, 2007, pp. 98-112.

46 "E no le parezca al que lee que es contradecirse lo uno a lo otro, porque los hombres, así como son de diversos juicios e condiciones, así miran y entienden las cosas diferenciadamente", dirá Oviedo. FERNÁNDEZ DE Oviedo, 1992, vol. IV, pp. 223-224.

47 Ibídem, vol. IV, p. 224.

48 Se trata en realidad de una mitificación de la historia de la conquista de América. Ver al respecto Fabregat Barrios, 2003, esp. pp. 79-80. Sobre la imagen del héroe en Gonzalo Fernández de Oviedo ver Coello de la Rosa, 2004 y 2005. El autor ha revisado ambos trabajos para incorporarlos a su libro Historia y ficción (2012). Sobre la "caracterización ficcional del personaje de Cortés" en sus Cartas de relación, ver PASTOR, 2008, esp. pp. 156-193 (cita de la p. 160).

49 Fernández de Oviedo, Historia, vol. IV, p. 16.

50 Ibídem, vol. IV, p. 66.

51 Ibídem, vol. IV, pp. 67-68.
} 
En otro momento, Oviedo compara a Cortés con Ciro y decide que el español reunía en su persona todas las características que el rey persa decía que debía tener un buen príncipe, cuyo oficio no era otro que "sobrepujar a los otros de prudencia, consejo, industria e fatiga, no ociosidad e quietud e voluptad" ${ }^{2}$. Cortés atesoraba grandes dotes militares, de modo que

sabía mandar sus ejércitos e a los que nuevamente venían a la obidiencia los enseñaba a obedecer con halagos e palabras dulces e con dádivas e gratificaciones cuando convenía. E tan manso e benigno era en la paz, como áspero e recio punidor de los que con el cuchillo habían de ser corregidos ${ }^{53}$.

Así, las hazañas de Cortés superaban a las del rey de Egipto llamado Sesostri, narradas por Diodoro Sículo ${ }^{54}$, y aun a las de "Viriato, nuestro español y extremeño" y las de "aquel espejo de caballería Julio César", ya que si bien a estos se debían grandes hechos, los habían llevado a cabo en "provincias e partes pobladas e proveídas e de las mejores del mundo", en el caso de César, y dentro de España, "en su patria", en el caso de Viriato. Por contra, Cortés había luchado con gran carencia de todo lo necesario, frente a grandes enemigos, gente "bárbara e belicosa e apacentada de carne humana" y en tierras muy nuevas y "dificultosas a la salud de los que nuevamente las conocen" ${ }^{55}$. Muchas habían sido por tanto las dificultades superadas y el mérito de las acciones de Cortés y sus "cortesanos" ${ }^{56}$, término con el que Oviedo quiere denominar en el futuro a los miembros de la hueste del conquistador de la Nueva España siguiendo la antigua costumbre de "nombrarse los soldados e nuevos pobladores en aquellas provincias que ellos conquistan" a partir del nombre de su capitán general, tal y como había ocurrido con

los españoles por Hispán, e a los asirios por Asur, e a los hebreos por Heber, e a los persas por Perseo, los armenios por Armenio, los troyanos por Troo, los alejandrinos por Alejandro, e los romanos por Rómulo, etc. E así, méritamente, conviene a estos mílites de Cortés que se les pegue tal ditado del propio nombre del linaje de Hernando Cortés ${ }^{57}$.

Sin lugar a dudas, uno de los momentos de mayor intensidad en la gesta de Cortés, tal y como la narra Oviedo siguiendo las cartas del conquistador, se encuentra en el cerco y toma de Temistitán. Al referirse a ello, Oviedo quiere recordar las palabras de Marco Tulio Cicerón a los romanos tras el castigo por la conjuración de Catilina. Cicerón había dicho que no quería ni premios, ni enseñas ni monumentos, sino per-

52 Ibídem, vol. IV, p. 80.

53 Ibídem.

54 Ibídem, vol. IV, p. 113. Oviedo se refiere a Sesostri, gran guerrero a quien, según Sículo, se debía la invención de las naves largas. Rememora a aquel al explicar cómo Cortés mandó hacer una zanja de más de media legua por la que llevar los bergantines que había mandado construir para el asedio de Temistitán.

55 Ibídem, vol. IV, p. 97.

56 Ibídem, vol. IV, p. 98.

57 Ibídem. El término de cortesanos aplicado a los soldados de Cortés tuvo escasa fortuna en la Historia, limitado a unas pocas páginas a partir de esta primera referencia. Oviedo olvidará rápidamente este apelativo, salvo dos menciones sueltas unos capítulos más adelante. 
manecer en la memoria de los romanos, porque así sus acciones "crecerán por las palabras, e durarán por las historias, tomando siempre una mayor fuerza". Del mismo modo lo debía pedir Cortés "a toda la nación de España" porque

es muy justa cosa que en la memoria de los que viven estén escriptas las hazañas e fechos memorables de Hernando Cortés, e que ellos las enseñen a sus hijos e aquellos a los que procedieren de ellos, e de una edad a otra e de tiempo en tiempo, siempre estén acordadas e perpetuadas en la mente de los humanos, allende de lo que puede estar o quedar escripto por mí o por otro más competente historiador ${ }^{58}$.

Para Oviedo no había ocurrido nada en la Historia equiparable al cerco de Temistitán: ni la destrucción de Sagunto por Aníbal, de Numancia por Escipión el Africano, de Troya por Agamenón o de Jerusalén por el emperador Tito ${ }^{59}$. Se trata de otro ejemplo de la idea de superación por parte de Castilla de lo que griegos y romanos habían llegado a hacer, una constante, podríamos decir, en la imagen oviedense del imperio español gracias precisamente al Nuevo Mundo ${ }^{60}$.

Conforme el personaje de Cortés va creciendo y tomando forma a lo largo del libro 33, su imagen se irá completando con otros aspectos. Nuevas virtudes irán adornando a otras que ya habían aparecido previamente ${ }^{61}$. Muy pronto Oviedo destaca del extremeño su habilidad, su condición de gran diplomático u hombre de buenas palabras. Cuando Cortés insiste en conquistar Nueva España después de salir de Temistitán y se hace con el control de la provincia de Tepeaca, Oviedo resalta el papel desempeñado por los indígenas aliados de Tascalteca (Tlaxcala), Churultecal y Guajocingo (Huejotzingo),

sin los cuales fuera por demás tentarse tal empresa, segund el poco número de los españoles a respecto de los contrarios; pero la buena maña de Cortés e sus buenas palabras pudieron adquirir el amistad de los confederados, juntamente con la antigua enemistad que ya ellos tenían contra los de Culúa e Tepeaca ${ }^{62}$.

Pero, además, es interesante ver cómo evoluciona en Oviedo el personaje de Cortés también en otros aspectos. Conforme pasan las páginas la imagen del extremeño como conquistador ganará en matices. Así, cuando Cortés, entre gesta y gesta, encuentra ocasión para la fundación de algún asentamiento Oviedo lo retrata como

\footnotetext{
58 Ibídem, vol. IV, p. 142.

59 Ibídem, vol. IV, pp. 142-143 y 151-152.

60 Este aspecto ha sido resaltado por otros autores como LAín ENTRALGO, 1979, pp. 216-217 y, sobre todo, Carrillo Castillo, 2004, pp. 80-116.

61 Cortés aparece retratado en Oviedo como alguien dotado de un gran ingenio para "las cosas de la guerra", de modo que aunque ignorase lo que Flavio Vegecio o Catón u otros escribieran sobre el arte militar, él "naturalmente nació para enseñar a otros muchos lo que en ella se debe hacer", FERNÁNDEZ DE OvIEDO, 1992, vol. IV, p. 98. A ello se había referido también previamente al narrar cómo Cortés había construido unos ingenios de madera a los que Vitruvio y Flavio Vegecio se referían como "testugines o tortugas". Oviedo duda de que Cortés conociera estos textos, pero "su ingenio e habilidad era a más que eso bastante", pp. 62-63.

62 Ibídem, vol. IV, p. 75. Hay otros pasajes muy claros en este mismo sentido, como por ejemplo el del capítulo 9. En cuanto a Culúa, sería Culhuacán o Colhuacán, mientras que Tepeaca sería la provincia de Tepanecas.
} 
un "apercibido e prudente poblador" o como alguien con "el cuidado e diligencia grande e la astucia de buen poblador" ${ }^{63}$. En la medida en que el relato avanza Oviedo va moldeando el personaje literario y son los propios acontecimientos narrados por Cortés en sus Cartas los que dan pie al cronista a ir presentando al conquistador en su condición de extraordinario hombre de armas, persona hábil con las palabras, buen poblador, etc... En definitiva, el personaje se va conformando al ritmo en que Oviedo lee el testimonio de Cortés y lo traslada a su Historia, comentándolo y valorándolo.

Con todo, en Oviedo el personaje de Cortés tiene también sus pequeñas sombras más allá de lo que hemos visto relacionado con Diego Velázquez. Oviedo cuestiona en más de una ocasión las afirmaciones de Cortés sobre aspectos relacionados con los conocimientos de historia natural. Así ocurre con la belleza que Cortés atribuye a las ciudades ubicadas en los llanos y que Oviedo cuestiona, o con datos geográficos concretos como la ubicación de una cordillera u otros similares. Algo parecido ocurre cuando explica el por qué del nombre de Nueva España, que Cortés atribuye - equivocadamente en opinión de Oviedo - a la mucha similitud con la península ${ }^{64}$. Son pequeños detalles que en este caso parecen querer reforzar más la imagen del propio cronista como conocedor de la historia natural del Nuevo Mundo que completar la figura o el personaje de Cortés ${ }^{65}$.

A pesar de todo, si hay algo que caracteriza al libro 33 de la Historia de Oviedo es el ser el lugar en el que el cronista construye la imagen de Cortés como gran conquistador, algo que no se cuestiona, sino que, bien al contrario, se resalta constantemente.

\section{CONCLUSIONES}

En conclusión, la construcción del personaje de Cortés en la Historia de Oviedo camina paralelamente al proceso de escritura de la crónica. En la Historia encontramos una evolución en lo que a la imagen de Cortés se refiere que se ve influida por el contenido de las Cartas que Oviedo va trasladando al argumento de su libro 33 y por pasajes concretos e ideas que acuden a la mente del cronista. El empleo del término cortesanos referido a los seguidores de Cortés es un ejemplo. Su uso queda prácticamente reducido a tres capítulos del libro 33, después de que Oviedo no lo empleara en los primeros veinte y se olvidara de él en los sucesivos.

En este sentido, aunque nos falta una edición crítica de la Historia que arroje más luz sobre el proceso de escritura de esta magna obra, parece como si la reescritura del cronista se hubiera centrado más en cuestiones de estructura de la obra y en la acumu-

63 Ibídem, vol. IV, pp. 170-171 y 189 respectivamente.

64 Los pasajes referidos se pueden ver en FERnández DE Oviedo, 1992, vol. IV, pp. 25, 27 y $82-83$ respectivamente.

65 Hay también algún otro lugar y contexto en que Oviedo corrige a Cortés. Así ocurre cuando Oviedo alude a los intentos de Cortés por encontrar el estrecho hacia la Especiería en la costa entre el río Pánuco y Florida y de allí hasta Bacallaos a partir de un mapa que él tenía. Oviedo explica lo equivocado de la suposición, aunque culpa a quien informara a Cortés, que era "mejor capitán e más diestro en las cosas de la guerra" que "experto cosmógrafo al que tal le dijo", Ibídem, vol. IV, p. 189. Otro caso lo podemos ver cuando Cortés afirma que algunos soldados hablaban con desánimo de la guerra. Oviedo dice que son gentes que "antes supieran padecer mil muertes que decir tales palabras", vol. IV, p. 136. 
lación de nuevos testimonios que en una reelaboración que buscara homogeneizar los juicios arrojados por el autor sobre acontecimientos históricos o personajes del proceso de la conquista. No existe en Oviedo una reescritura del sentido de sus páginas. No la hay al menos en lo que a Cortés se refiere. Oviedo da por buenas sus páginas y no vuelve sobre ellas con el objetivo de evitar esa imagen dinámica, cambiante y en ocasiones hasta contradictoria del conquistador de la Nueva España. Oviedo acumula testimonios fidedignos, como si la escritura de la Historia fuera un proceso judicial en el que se van recopilando pruebas - aspecto este ya resaltado por otros autores como Jesús Carrillo Castillo- . Tal vez por ello mismo, Oviedo cuando regresa sobre lo ya escrito lo hace con el ánimo de corregir alguna fecha o añadir algún dato, no para cambiar el contenido del testimonio recogido.

Según avanza el resumen que Oviedo hace de las Cartas de Cortés, la figura de éste como un excelente militar va cobrando la forma de un héroe y, así, Oviedo lo compara con grandes figuras legendarias. La primera idea de un Cortés desleal para con Diego Velázquez se verá mitigada en los capítulos en los que se impone claramente el conquistador, el héroe militar. Es cierto que el Descubrimiento no es un mérito que corresponda a Cortés y Oviedo incide en ello en más de una ocasión también como forma de resaltar la figura de Cristóbal Colón. Pero conforme avanza el libro 33, la imagen de Cortés como gran conquistador terminará por imponerse en el cronista madrileño y esto resolverá las dudas que podía haber sobre él con motivo de su deslealtad para con su superior. Y esto será así hasta que Cortés cometa el error de cuestionar la autoridad de Velázquez como legítimo representante del rey y se atreva a escribir al monarca sugiriéndole que él indagaría sobre el posible mal hacer de aquel y enviaría a Cuba a apresarlo si podía demostrarlo. Cortés podía ser un gran conquistador y gobernador de Nueva España, pero en Cuba "no tenía qué hacer".

Tal vez podamos coincidir con Octavio Paz en la necesidad de que "el conquistador debe ser restituido al sitio a que pertenece con toda su grandeza y todos sus defectos, a la Historia" ${ }^{66}$. De momento, esperamos haber arrojado algo de luz sobre la elaboración del personaje que llevara a cabo Gonzalo Fernández de Oviedo, así como sobre algunas de las razones que le impulsaron a ello.

\section{REFERENCIAS BIBLIOGRÁFICAS}

Arellano, Ignacio

2007 Editar a Calderón. Madrid - Frankfurt am Main. Iberoamericana - Vervuert.

BenNASSAR, Bartolomé

2002 Hernán Cortés. El conquistador de lo imposible. Madrid. Temas de Hoy.

Carrillo Castillo, Jesús

2004 Naturaleza e Imperio. La representación del mundo natural en la "Historia general y natural de las Indias” de Gonzalo Fernández de Oviedo. Madrid. Ediciones Doce Calles.

66 Citado por Mira Caballos, 2010, p. 47. 
Coello de la Rosa, Alexandre

2004 "Héroes y villanos del Nuevo Mundo en la Historia general y natural de las Indias de Gonzalo Fernández de Oviedo y Valdés”. Anuario de Estudios Americanos. Sevilla, $\mathrm{n}^{\mathrm{o}} 51.2$, pp. 599-618.

2005 "El héroe cidiano en la conquista de San Juan de Puerto Rico según la Historia general y natural de las Indias de Gonzalo Fernández de Oviedo y Valdés (15111513)". Anales de Literatura Hispanoamericana. Madrid, n 34, pp. 87-108.

2012 Historia y ficción. La escritura de la Historia general y natural de las Indias de Gonzalo Fernández de Oviedo y Valdés (1478-1557). Valencia. Universitat de València.

CORTÉs, Hernán

1958 Relaciones de Hernán Cortés a Carlos V sobre la invasión de Anahuac.[1519-1526].

Guzmán (ed.). México. Anahuac.

1993 Cartas de relación [1519-1526]. Delgado Gómez (ed.). Madrid. Castalia.

Delgado Gómez, Ángel

1993 “Noticia bibliográfica”, en su edición de CoRTÉs, Cartas de relación. Madrid. Castalia, pp. 73-89.

Delgado Larios, Almudena

1990 "Bibliografía sobre Hernán Cortés (1930-1985)”. En Hernán Cortés. Hombre de empresa. Valladolid. Publicaciones de la Casa Museo de Colón - Seminario Americanista de la Universidad de Valladolid, pp. 211- 228.

ElLiotT, John H.

1965 La España imperial (1469-1716). Barcelona. Vicens Vives.

1971 "Introduction". En CoRTÉs, Letters from Mexico. PAGUen (ed.). New York. Orion Press - Grossman Publishers, pp. XI-XXXIII.

Fabregat Barrios, Santiago

2003 "Presencia y función de los mitos clásicos en la Historia general y natural de las Indias de Gonzalo Fernández de Oviedo y Valdés". EPOS. Madrid, nº 19, pp. 67-88.

FERNÁNDEZ DE OviEDo, Gonzalo

1992 Historia general y natural de las Indias [1535]. Pérez de Tudela Bueso (ed.). Madrid. Atlas, 5 vols.

2010 Sumario de la Natural Historia de las Indias [1526]. BAraibar (ed.). Madrid Frankfurt am Main. Iberoamericana - Vervuert.

GuZMÁn, Eulalia

1958 Ver CORTÉs, Hernán.

Laín Entralgo, Pedro

1979 "Fernández de Oviedo ante la naturaleza del Nuevo Mundo". En Gallego Morell SORIA - MARín (eds.), Estudios sobre literatura y arte dedicados al profesor Emilio Orozco Díaz. Granada. Universidad de Granada, vol. II, pp. 215-230.

LAS CASAs, Bartolomé de

1951 Historia de las Indias. [1559] Millares - Hanke (eds.). México. Fondo de Cultura Económica, 3 vols.

LeÓn Portilla, Miguel

1974 “Quetzalcoatl - Cortés en la conquista de México". Historia Mexicana. México, no 24, pp. 13-35. 
LóPez de Gómara, Francisco

2000 La conquista de México [1552]. Rojas (ed.). Madrid. Dastin.

MADARIAGA, Salvador de 1975 Hernán Cortés [1941]. Madrid. Espasa-Calpe.

Martínez, José Luis

1990 Hernán Cortés. México. Universidad Nacional Autónoma de México - Fondo de Cultura Económica.

Mira Caballos, Esteban

2010 Hernán Cortés: el fin de una leyenda. Trujillo. Palacio Barrantes Cervantes.

Myers, Kathleen Ann

2007 Fernández de Oviedo's Chronicle of America. A New History for a New World. Austin. University of Texas Press.

Orozco y Berra, Manuel

1880 Historia antigua y de la conquista de México. México. Tip. de Gonzalo A. Esteva.

1938 Historia de la dominación española en México. México. Antigua Librería Robredo, de José Porrúa e Hijos, 4 vols.

PASTOR, Beatriz

2008 El segundo descubrimiento. La conquista de América narrada por sus coetáneos (1492-1589) [Primera versión: El discurso narrativo de la conquista: mitificación y emergencia. La Habana. Casa de las Américas, 1983]. Barcelona. Edhasa.

Ramos, Demetrio

1992 Hernán Cortés. Mentalidad y propósitos. Madrid. Rialp.

REYNOLDS, Winston A.

1978 Hernán Cortés en la Literatura del Siglo de Oro. Madrid. Editora Nacional.

Rojas, José Luis de

2000 “Introducción”. En LóPEZ de GÓMARA, La conquista de México. Madrid. Dastin, pp. 5-38.

SAgarra Gamazo, Adelaida

1990 "El obispo Fonseca: un personaje enfrentado a Cortés, en la crónica de Bernal Díaz del Castillo". En Hernán Cortés. Hombre de empresa. Valladolid. Casa Museo de Colón - Seminario Americanista de la Universidad de Valladolid, pp. 25-51.

SERÉs, Guillermo

2005 La conquista como épica colectiva. La obra de Bernal Díaz del Castillo. Madrid. Ediciones del Orto.

TomÁs y VAliente, Francisco

1988 “Las ideas políticas del conquistador Hernán Cortés”. En Solano (coord.), Proceso histórico al conquistador. Madrid. Alianza, pp. 165-181.

VARgas Machuca, Bernardo

2003 Milicia y descripción de las Indias. [1599]. Cuesta Domingo - LóPEZ-Ríos Fernández (eds.). Valladolid. Universidad de Valladolid.

WAGNER, Henry R.

1944 The Rise of Fernando Cortés. Berkeley. The Cortés Society - Bancroft Library.

Zavala, Silvio

1964 Los intereses particulares en la conquista de la Nueva España. México. UNAM.

1985 "Hernán Cortés y la justificación de su conquista”. Quinto Centenario. Madrid, nº 9, pp. 15-36. 